\title{
The effectiveness of Er.Cr.Ysgg laser in sustained dentinal tubules occlusion using scanning electron microscopy
}

\begin{abstract}
Aim: To evaluate and compare the effect of Er.Cr.YSGG Laser in sustained dentinal tubules occlusion with different treatment methods used on exposed dentin surface at different time intervals using scanning electron microscopy (SEM).

Material and methods: 26 natural posterior teeth were sectioned, prepared and embedded in acrylic resin. Samples were polished to remove the enamel layer and randomly divided into 5 groups: Group A- negative control group $(n=4)$, Group B- Desensitizing toothpaste (Colgate Sensitive Pro-relief, Colgate), Group 3- Desenstizing Paste (MI paste, GC), Group D- Desensitizing varnish (VivaSens ${ }^{\circledR}$, IvoclarVivadent), Group E- Er.Cr.YSGG laser (Waterlase ${ }^{\circledR}$, Biolase Inc.). Each group was treated according to the manufacturer instructions and subjected to aging process. Dentin occluded surfaces were examined using (SEM). Micrographs were taken in three intervals; immediately after treatment, after two weeks, and after one month. Qualitative assessment was done for the micrographs to evaluate the surface characteristics.
\end{abstract}

Results: The immediate SEM micrographs of showed complete obliteration of most of the dentinal tubules in all treatments used. Micrographs taken after two weeks showed sustained occluded dentinal tubules only in the toothpaste group and Er.Cr.YSGG Laser group. Lastly, after one-month the Er.Cr.YSGG Laser group had the only dentinal tubules that remained completely occluded or at least constricted.

Conclusion: Er.Cr.YSGG laser showed constant results in occluding dentinal tubules over a period of one month.

Clinical significance: Lasers have been found to be effective for long term relief from dentinal hypersensitivity.

Keywords: tooth sensitivity, dentinal tubules, dentinal hypersensitivity, desensitizing agents, Er.Cr.YSGG laser
Volume 7 Issue 6 - 2017

\author{
Al Hanouf Al Habdan,' Amal Al Awdah,' Al \\ Anoud Al Meshari, ${ }^{2}$ Lamia Mokeem, ${ }^{2}$ Reem \\ Al Saqat ${ }^{2}$ \\ 'Department of Restorative Dentals Sciences, King Saud \\ University, Saudi Arabia \\ ${ }^{2}$ College of Dentistry, King Saud University, Saudi Arabia
}

Correspondence: Al Hanouf Al Habdan, Department of Restorative Dental Sciences, King Saud University, Riyadh, Saudi Arabia,Tel 967000000000,Email alhanouf@habdan.com

Received: July 23, 2017 | Published: July 28, 2017

\section{Introduction}

Tooth sensitivity is one of the most disturbing clinical conditions; the terms Dentin Sensitivity or Dentinal Hypersensitivity have been used to describe this condition. Dentinal hypersensitivity was defined as short, sharp pain arising from exposed dentin in response to thermal, evaporative, tactile, electrical, osmotic or chemical stimuli. ${ }^{1}$ It is generally involves facial surfaces of the teeth near cervical border and most commonly in canines and premolars. ${ }^{1}$ It could be caused by either enamel or cemental loss. Enamel loss is a result of occlusal wear, dietary erosion, and improper tooth brushing technique, abfraction and parafunctional habits. Moreover, gingival recession, periodontal disease, root planning and periodontal surgery may cause cemental loss. ${ }^{2-4}$ Many theories were proposed to explain the causes of dentinal hypersensitivity. One of the most accepted theories is The Hydrodynamic Theory by Brännström. ${ }^{5}$ It states that the fluid flow within the dentinal tubules can excite a painful stimulus. ${ }^{5}$ Cold causes a rapid increase in this flow which may be interpreted as pain by the patient when there dentinal tubules are exposed. ${ }^{6}$ Although various treatment methods of dentin hypersensitivity are mentioned in literature, they must meet certain criteria in order to be efficient. These methods should be easy to apply, have a permanent effect, must act rapidly, neither irritate the pulp nor cause tooth discoloration nor should be cost effective. Treatment options include desensitizing by blocking pulpal sensory nerves or occluding the open dentinal tubules. ${ }^{2}$ The potassium nitrate desensitizing products have the ability to work by blocking the synapse between nerve cells, reducing nerve activation, and the related pain. On the other hand, many agents have been known to occlude dentinal tubules such as Sodium fluoride, potassium oxalate and Calcium phosphate. Also varnishes, cements, adhesive materials and lasers have been known to occlude the dentinal tubules. ${ }^{2}$ There are many types of lasers used in dentistry, which have been divided into hard lasers and soft or cold lasers. Hard lasers are Carbon dioxide (CO2), Neodymium Yttrium Aluminum Garnet (Nd: YAG), and Er: YAG. These lasers can be applied for hard and soft tissue but they have the potential to damage the pulp along with their high cost. On the other hand, Soft or cold lasers which were based on the semiconductor diode devices that deliver laser in non-thermal mean termed as low-level laser therapy (LLLT) or biostimulation. ${ }^{7}$ Lasers in general have many implications on dental specialties, Aesthetic gingival re-contouring and crown lengthening in periodontal treatments, photodynamic therapy for malignancies, exposure of unerupted and partially erupted teeth in orthodontic treatments, removal of inflamed, hypertrophic tissue, miscellaneous tissue removal in oral medicine. They also, showed a significant development in hard tissue treatment like Cavity 
preparation, caries, and restorative material removal in addition to treatment of dentinal hypersensitivity. ${ }^{7}$ Erbium. Chromium: Yttriumscandium-gallium-garnet laser (Waterlase ${ }^{\circledR}$ ) (CBIOLASE, Inc., USA) is the type of laser used in this study. It is a class 4 laser with a $2780 \mathrm{~nm}$ wavelength. This laser has both advantages on the care provider and recipient. Er.Cr:YSSG (Waterlase ${ }^{\circledR}$ ) laser is painless and the treatment could be provided without using local anesthesia. In addition, it is convenient, safe and precise. ${ }^{7,8}$ Er.Cr:YSSG laser (Waterlase ${ }^{\circledR}$ ) has multiple indications; in hard tissues it is used for caries removal, enameloplasty, hard tissue surface roughening or etching and bone surgical procedures. While in soft tissues, it can be used in procedures associated with pulpal tissues, excisional or incisional biopsies, exposure of un erupted teeth, gingivectomy, gingivoplasty and Frenectomy. ${ }^{9}$ Therefore, the availability of this type of laser in the dental clinic will serve the patient on many levels. However, in the literature there is not enough information about the effect of Erbium. Chromium: Yttrium-scandium-gallium-garnet lasers and their ability to reduce dentin sensitivity in comparison with other available clinical solutions of dentine hypersensitivity over a period of time. The objectives of this study were to evaluate the effect of Er.Cr.YSGG Laser (Waterlase ${ }^{\circledR}$ ) in sustained dentinal tubules occlusion and compare the effect of different treatment methods used on exposed dentin surface using Scanning electron microscopy (SEM) after different time intervals using SEM.

\section{Materials and methods}

Twenty-six posterior human teeth were used in this study. The teeth were extracted for orthodontic reasons. Samples were washed thoroughly after extraction and stored in dark glass container of $1 \%$ thymol solution at $4{ }^{\circ} \mathrm{C}$ till use. Roots were cut below the root furcation and removed using ISOEMT 2000 PRECISION SAW (BUEHLER 41, Waukegan Road, Lake Bluff, IL, USA). Teeth crowns were sectioned again mesio-distally to use both buccal and lingual surfaces for the experiment. Sectioned samples were mounted in acrylic self-cured resin where either buccal or lingual surface facing upward with the pulpal surfaces are embedded in the resin. Sample surfaces were subjected to different grits of abrasive disks to remove the enamel layer and expose the dentin (AUTOMATA Grinding and Polishing unit, JEANWIRTZ Gmbh \& Co. Charlottestrabe Dusseldorf W. Germany). Grinding started with continuous air-water irrigation using 320-grit, 400-grit disks respectively. Then the samples were polished by 600 -grit disk for 30 seconds each. The grinded samples were placed in Ultrasonicator (SONICER, Yoshida Dental Mfg
Co Ltd, Osaka, Japan) filled with distilled water for 15 minutes to remove the enamel debris. Then, the specimens were examined under light microscope (STEREO 80 Wildefield Microscope, SWIFT instrument inc, USA) to ensure complete enamel removal. Then each surface was etched by ethylenediaminetetraacetic acid (EDTA) (EDTA SOLUTION, Prevest Denpro, India) for one minute to ensure complete removal of the smear layer. Finally, the samples were randomly divided into four groups according to different management of dentin hypersensitivity and an extra negative control group. Group A- negative control group which remained without any intervention $(n=4)$, Group B- Desensitizing varnish (VivaSens ${ }^{\circledR}$, Ivoclar Vivadent, Schaan, Liechtenstein) (n=12), Group C- Desenstizing Paste (MI paste, GC America Inc., USA) ( $\mathrm{n}=12)$, Group D- Desensitizing toothpaste (Colgate Sensitive Pro-relief, Colgate, USA) ( $\mathrm{n}=12$ ), Group E- Er.Cr.YSGG laser (Waterlase ${ }^{\circledR}$, Biolase Inc., USA) $(\mathrm{n}=12)$. All the materials used in this study were applied according to their manufacturer's instruction. Laser used has a wavelength of $2.780 \mathrm{~nm}$ with a power of $0.25 \mathrm{~W}$ and $30 \mathrm{~Hz}$ frequency. The laser tip (Mz5, 6mm length) was applied perpendicular to the tooth surface and moved slowly along all surfaces of the tooth for $30 \mathrm{~s}$ with $5 \mathrm{~mm}$ distance from the surface. Each experimental group was randomly subdivided into three groups $(n=4)$ to record three different time intervals: immediately after the treatment, after two weeks and finally after one-month. The dentin-occluded surfaces were scanned with scanning electron microscope (SEM) (JEOL JSM-6360LV) using $20 \mathrm{kv}$ in 1500-fold magnification and the dimension of the picture side was $10 u m$. The reason behind subdividing each experimental group is because the samples will be damaged after preparation for scanning electron microscope (SEM) and cannot be used further in the study. The group description, material used, and their method of application were fully described in Table 1 . The specimens were immersed in $250 \mathrm{ml}$ artificial saliva (prepared as described by Cavalli et al. ${ }^{10}$ during the experiment at $37^{\circ} \mathrm{C}$ and kept in an incubator (Memmert universal oven, Germany). Saliva solution was changed weekly. Surface characteristics and the occlusion of the dentinal tubules were evaluated using SEM micrographs. These micrographs were ranked according to four descriptive categories adopted from Al-Saud et al. ${ }^{11}$ with some modification. These categories include: $\boldsymbol{\theta}=$ the dentinal tubules were mostly occluded; the dentinal surface is partially covered with film or precipitation or shows some surface alterations. $\boldsymbol{I}=$ the dentinal tubules are mostly occluded; the dentinal surface is devoid of film or precipitate. $2=$ the dentinal tubules are partially occluded and dentinal orifices are slightly smaller, with little or no debris. $3=$ all the dentinal tubules are widely opened with little or no debris.

Table I The experimental groups

\begin{tabular}{|c|c|c|c|c|}
\hline Group & Material & Composition & Action Mechanism & Method of Use \\
\hline$A(n=4)$ & Negative control & & & \\
\hline$B(n=\mid 2)$ & Colgate Sensitive Pro-relief $®$ toothpaste & $\begin{array}{l}\text { Arginine (Bicarbonate), } \\
\text { Calcium carbonate. }\end{array}$ & $\begin{array}{l}\text { Arginine activates bacteria } \\
\text { that neutralize acids and } \\
\text { calcium, along with saliva } \\
\text { to restore missing enamel. }\end{array}$ & $\begin{array}{l}\text { Apply with finger for I } \\
\text { minute then leave it for } \\
30 \text { minutes daily for } 2 \\
\text { weeks. }\end{array}$ \\
\hline$C(n=12)$ & MI Paste, GC® & $\begin{array}{l}\text { Recaldent (CPP-ACP) } \\
\text { calcium and phosphate. }\end{array}$ & $\begin{array}{l}\text { A special milk derived } \\
\text { phosphopeptide that binds } \\
\text { calcium and phosphate to } \\
\text { tooth surface. }\end{array}$ & $\begin{array}{l}\text { Apply with finger for } 4 \\
\text { minutes the leave it for } \\
30 \text { minutes daily. }\end{array}$ \\
\hline$D(n=12)$ & VivaSense $®$ desensitizing varnish & $\begin{array}{l}\text { Liquid varnish containing } \\
\text { potassium fluoride, } \\
\text { polyethylene glycol } \\
\text { dimethacrylate, and } \\
\text { other methacrylates. }\end{array}$ & $\begin{array}{l}g_{\text {Precipitation of calcium }} \\
\text { ions, potassium fluoride } \\
\text { and proteins in the dentinal } \\
\text { fluids. }\end{array}$ & $\begin{array}{l}\text { One drop applied by } \\
\text { microbrush for } 10 \\
\text { Iseconds then reapplies } \\
\text { after one week. }\end{array}$ \\
\hline
\end{tabular}


Table Continued...

\begin{tabular}{|c|c|c|c|c|}
\hline Group & Material & Composition & Action Mechanism & Method of Use \\
\hline$E(n=12)$ & Waterlase $®$ Laser & Er.Cr:YSGG laser & $\begin{array}{l}\text { Energized water molecules } \\
\text { vaporize, causing a } \\
\text { biological ablation of hard } \\
\text { and soft tissue. Melting of } \\
\text { the peritubular dentin. }\end{array}$ & $\begin{array}{l}\text { Wavelength }=2.780 \text {. } \\
\text { Tip size }=\mathrm{Mz} 5,6 \mathrm{~mm} \\
\text { length. Power }=0.25 \mathrm{~W} \text {. } \\
\text { Frequency }=30 \mathrm{~Hz} \text {. Mode: } \\
\text { H.Air and water } \%= \\
0 \% \text {. Distance to target= } \\
5 \mathrm{~mm} \text {. The laser tip was } \\
\text { applied perpendicular to } \\
\text { the tooth surface and } \\
\text { moved slowly along all } \\
\text { surfaces of the tooth } \\
\text { for } 30 \mathrm{~s} \text {. }\end{array}$ \\
\hline
\end{tabular}

\section{Results}

Dentin surfaces showed different amounts of dentinal tubules occlusion with different methodology used and time. All the tested material showed an effect on the dentinal tubules patency to a different degree. The micromorphlogical ranking of all the groups are demonstrated in (Table 2).

Table 2 The micrographical ranking of all the groups

\begin{tabular}{|c|c|c|c|c|c|c|}
\hline \multirow{2}{*}{ Treatment } & & \multicolumn{4}{|c|}{ Categories } & \multirow{2}{*}{- total } \\
\hline & & 0 & I & 2 & 3 & \\
\hline \multirow[t]{3}{*}{ Vivasense } & Immediate & 3 & 0 & 1 & 0 & 4 \\
\hline & 2-weeks & 0 & 0 & 4 & 0 & 4 \\
\hline & One-month & 0 & 0 & 0 & 4 & 4 \\
\hline \multirow[t]{3}{*}{ MI Paste } & Immediate & 3 & 0 & 0 & I & 4 \\
\hline & 2-weeks & 0 & 4 & 0 & 0 & 4 \\
\hline & One-month & 0 & 0 & 0 & 4 & 4 \\
\hline \multirow[t]{3}{*}{ Colgate toothpaste } & Immediate & 3 & 0 & 1 & 0 & 4 \\
\hline & 2-weeks & 0 & 0 & 3 & I & 4 \\
\hline & One-month & 0 & 0 & 4 & 0 & 4 \\
\hline \multirow[t]{3}{*}{ Waterlase } & Immediate & 0 & 4 & 0 & 0 & 4 \\
\hline & 2-weeks & 0 & 4 & 0 & 0 & 4 \\
\hline & One-month & 0 & 4 & 0 & 0 & 4 \\
\hline
\end{tabular}

\section{Immediate results}

SEM micrographs of the negative control (Group A) showed fully opened dentinal tubules (Figure 1). The VivaSense ${ }^{\circledR}$ group (Group B) showed complete coverage of dentinal tubules with the resin material without any morphological changes (Figure 2). Dentin samples treated with MI paste (Group C) (Figure 3) revealed some dentinal tubules coverage with the treated paste material that precipitates on the dentin tubules with other tubules remained fully opened and unaffected. Same presentation was found in the Colgate ${ }^{\circledR}$ toothpaste group (Group D) (Figure 4) where the majority of the dentinal tubules were fully opened and unaffected. However, there was some coverage of the dentinal tubules opening with the paste material. All dentin samples treated with Waterlase ${ }^{\circledR}$ (Group E) (Figure 5) showed complete occluding and obliteration of most of the dentinal tubules with few surface precipitate. The other remaining tubules exhibited some alterations and constriction of their diameter.

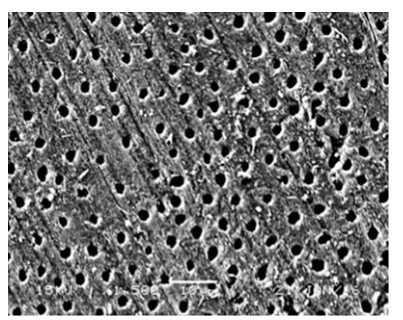

Figure I SEM micrograph of the negative control sample showing fully opened dentinal tubules.

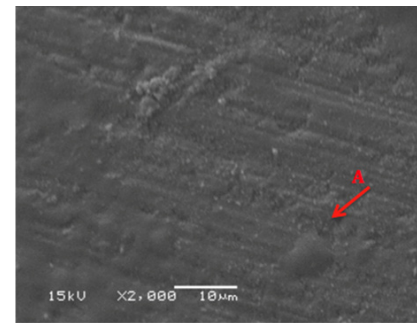

Figure 2 SEM micrograph of dentine samples treated with VivaSense showing complete dentinal tubules coverage with resin material $(\mathrm{A})$.

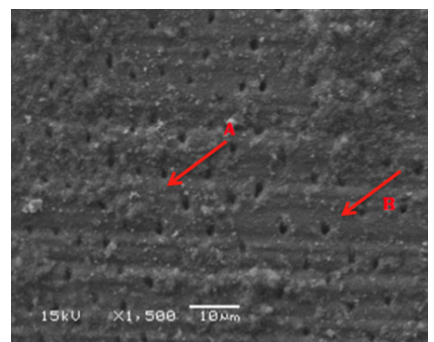

Figure 3 SEM micrograph of dentine samples treated with MI Paste showing some of the dentinal tubules coverage with MI Paste material (A) and other fully opened unaffected dentinal tubules (B).

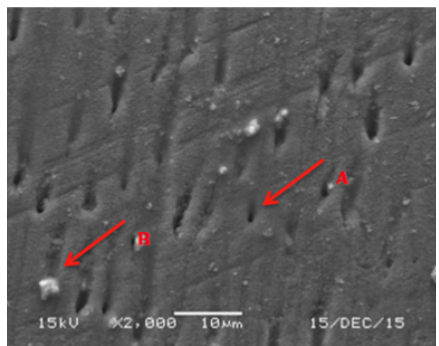

Figure 4 SEM micrograph of dentine samples treated with Colgate toothpaste showing fully open unaffected dentinal tubules $(A)$ and some dentinal tubules obliteration with the paste material (B). 


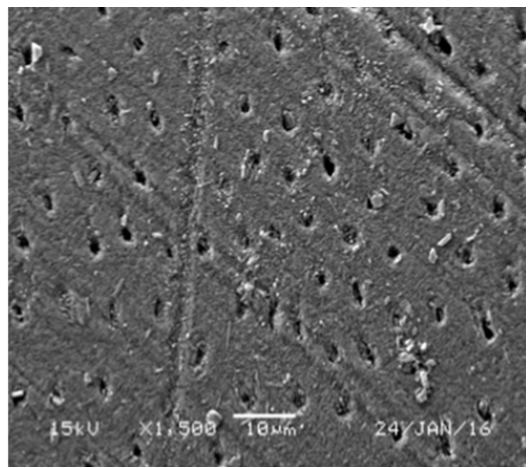

Figure 5 SEM micrograph of dentine samples treated with Waterlase showing completely occluded dentinal tubules $(A)$ and partially occluded dentinal tubules (B).

\section{Two-week results}

SEM micrographs of the VivaSense ${ }^{\circledR}$ group (Group B) showed partially occluded dentinal tubules and dentinal tubules diameter were narrower with little or no debris. However, the occluding effect was less than what have been seen in the immediate application results of the same group (Figure 6). Dentin samples treated with MI Paste (Group C) shows constricted dentinal tubules with some of them are completely obliterated with dentin-like material without any paste precipitate remains on the surface (Figure 7). On the other hand, the Colgate ${ }^{\circledR}$ toothpaste group (Group D) showed more open and unaffected dentinal tubules (Figure 8). Finally, the Waterlase ${ }^{\circledR}$ group (Group E) showed completely occluded dentinal tubules with only few remained slightly opened (Figure 9).

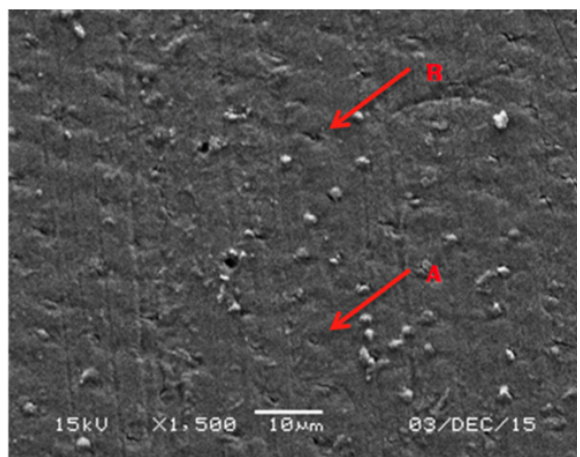

Figure 6 SEM micrograph of dentine samples treated with VivaSense after 2-weeks.

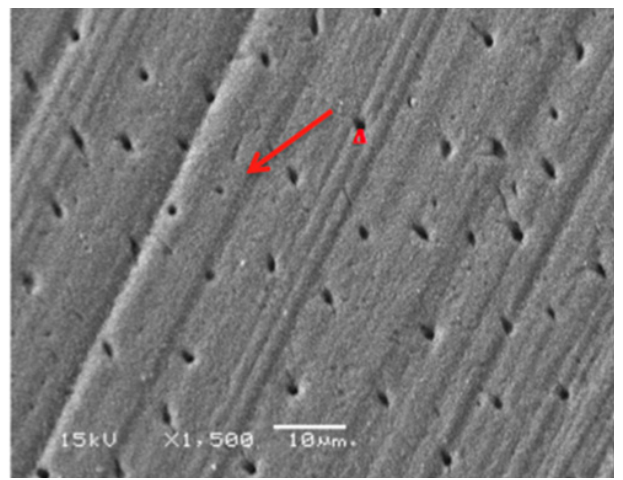

Figure 7 SEM micrograph of dentine samples treated with MI Paste after 2-weeks showing reduced constricted dentinal tubules opening (A).

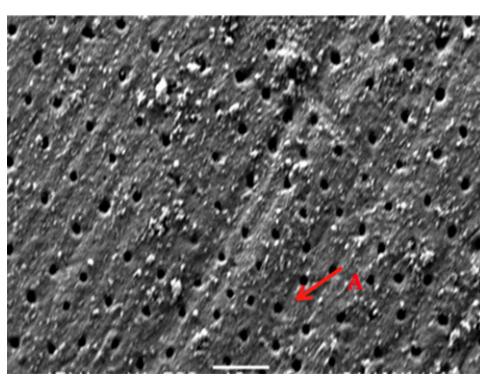

Figure 8 SEM micrograph of dentine samples treated with Colgate toothpaste after 2-weeks showing fully opens unaffected dentinal tubules (A).

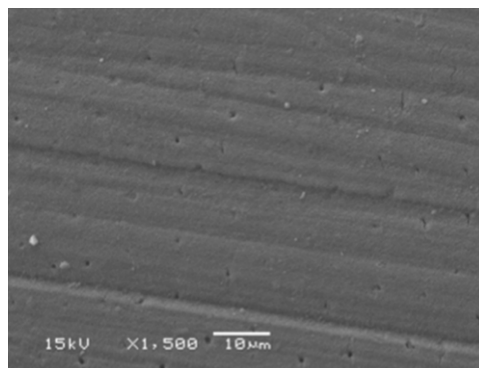

Figure 9 SEM micrograph of dentine samples treated with Waterlase after 2-weeks showing completely occluded dentinal tubules.

\section{One-month results}

SEM micrographs showed widely opened dentinal tubules in dentin samples treated with VivaSense ® (Group B) and MI Paste (Group C) without the presence of any resin or paste precipitate (Figures $10 \& 11)$. Colgate ${ }^{\circledR}$ toothpaste group (Group D) showed occluded dentinal tubules with paste precipitates on the surface (Figure 12). Lastly, samples irradiated with Waterlase ${ }^{\circledR}$ (Group D) demonstrated that most dentinal tubules remained completely occluded or at least constricted (Figure 13).

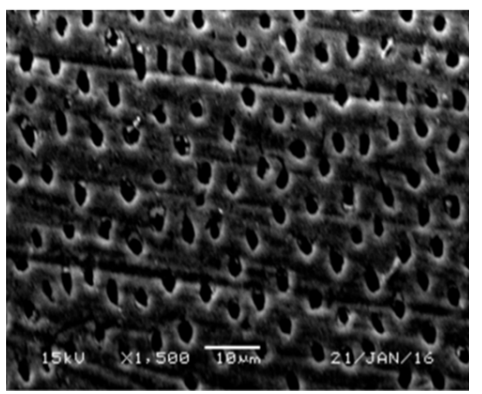

Figure IO SEM micrograph of dentine samples treated with VivaSense after one month showing widely open dentinal tubules orifices.

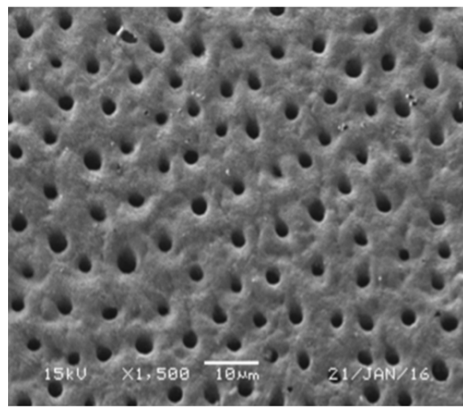

Figure II SEM micrograph of dentine samples treated with MI Paste after one month showing widely open dentinal tubules orifices. 


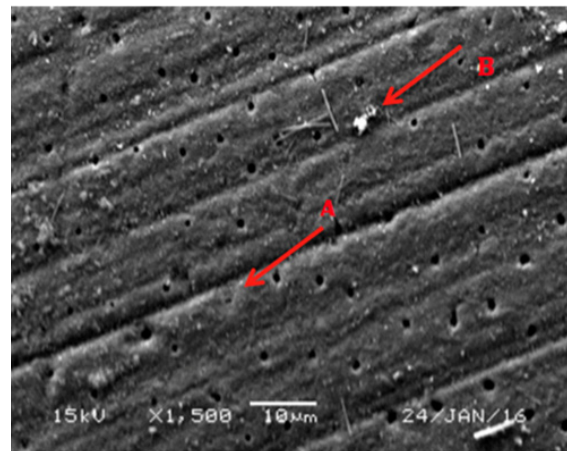

Figure I 2 SEM micrograph of dentine samples treated with Colgate toothpaste after one month showing slightly constricted dentinal tubules orifices (A) with some paste precipitate (B).

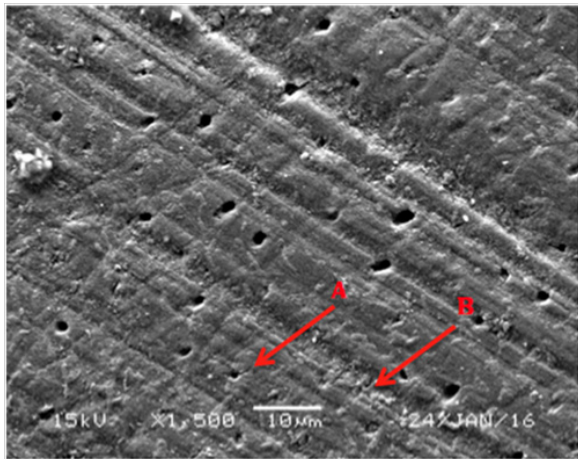

Figure 13 SEM micrograph of dentine samples treated with Waterlase after one month showing constricted dentinal tubule orifice $(A)$ and completely occluded dentinal tubules (B).

\section{Discussion}

Dentinal hypersensitivity could be decreased by minimizing the fluid movements inside the dentinal tubules which in turn disturbs the stimuli transmission to the odontoblastic process. ${ }^{5}$ Many methods can be applied for occluding dentinal tubules, first by sealing the dentin surface or by occluding within their orifices or occluding in the subsurface dentin within their tubules. ${ }^{2,3}$ In this study, different treatment modalities of dentinal hypersensitivity were experienced and examined in different time intervals, immediately, after two weeks, and one month using SEM. All the samples were prepared by etching the dentin surface with $0.5 \mathrm{ml}$ EDTA before treatment. This important step is to make sure that any other materials or smear layer, smear plugs were removed from prepared surface dentin that can cause confusion with treatment materials. Sensitive dentin always has open wide tubules, so the etching process aimed to stimulate the open tubules of the sensitive dentin..$^{12}$ Among the treatment methods used, the only method sustained the occluded dentinal tubules over the tested period of time is the Er.Cr.YSGG laser (Waterlase ${ }^{\circledR}$ ) group. This comes in agreement with several studies. ${ }^{7-17}$ Raichur et al. ${ }^{18}$ compared diode laser, stannous fluoride gel, and potassium nitrate gel in the treatment of dentinal hypersensitivity over a period of 6 months. Among all tested groups, only the laser group sustained occluded dentinal tubules throughout this period. ${ }^{18}$ The energy emitted from Er.Cr:YSGG laser has 5 to 100 pulses per second. It released from the tip of the hand-piece along with a fine water spray. Laser photons energize water molecules within the target tissue and from the spray on the tissue surface. Energized water molecules vaporize, causing a biological and cool ablation of hard and soft tissue. This action will cause melting of the peritubular dentin and can occlude dentinal tubules totally or partially, therefore these melting processes reduce patients' hypersensitivity and sustain the occluded tubules..$^{19}$ Bela et al. ${ }^{13}$ found that Er:YAG laser does not affected the compositional structure of the mineral content of the tubules. ${ }^{13}$ VivaSense ${ }^{\circledR}$ desensitizing varnish, covered the dentinal tubules without changing the morphology in the immediate results of this study. This comes in agreement with Al-Saud et al. ${ }^{11}$ were this varnish showed an effect in occluding immediately the dentinal tubules. VivaSense ${ }^{\circledR}$ is a film like varnish. A tight block of the dentinal tubules is achieved by precipitation of calcium ions, potassium fluoride and proteins in the dentinal fluids. ${ }^{20}$ Although this method of treatment was effective immediately, the two weeks and one month result for this group showed that few or no resin precipitate presented and dentinal tubules were partially occluded. This might be due to the washed out effect of this varnish. This deterioration has been stated in previous studies. ${ }^{1-18}$ MI paste and Colgate sensitive pro-relief® toothpaste groups showed opened dentinal tubules in the SEM micrographs when tested immediately. MI paste is a special milk derived phosphopeptide that binds calcium and phosphate to tooth surface. It is water based sugar free cream that is applied to the tooth surface or oral cavity. MI paste with recaldent casein phosphopeptides and amorphous calcium phosphate (CPPACP) improve fluoride uptake as well as soothing sensitive surfaces. ${ }^{21}$ While Colgate Sensitive Pro-relief ${ }^{\circledR}$ toothpaste positively charged arginine molecules bind to the negatively charged surface of dentin. They help attract calcium to form a calcium-rich mineral layer on the dentin surface, which occludes tubules. The occlusion protects dentin fluid from exposure to external stimuli, thus stopping fluid movement in the tubules. This blocking of the fluid movement removes the cause of pain and discomfort. ${ }^{22}$ After two weeks, the dentin samples treated with MI Paste showed constricted dentinal tubules with some of them are completely obliterated with dentin-like material without any paste precipitate remains on the surface. The opposite was seen with the Colgate ${ }^{\circledR}$ toothpaste group where there were more open and unaffected dentinal tubules. Failure of these materials to sustain occluded dentinal tubules was also noted in other studies. Palazon et al. ${ }^{17}$ studied the immediate and short-term effects of laser neodymiumdoped yttrium aluminum garnet (Nd:YAG) irradiation and different in-office desensitizing treatment on dentin tubule occlusion. They found that only laser irradiation was capable of immediately sealing the dentinal tubules; however, none of the other treatments showed efficacy in maintaining tubule occlusion after the chemical and mechanical challenges. This in-vitro study has limitations as the oral environment differs from the laboratory conditions. The brushing technique of the patent, type of toothbrush used, chewing hard food and oral habits may affect the results of the desensitizing treatment used over time. Further studies are recommended to calculate the depth of occlusion for dentinal tubules in each method and its ability to sustain for more than 6 months in the oral cavity environment.

\section{Conclusion}

Er.Cr.YSGG laser (Waterlase ${ }^{\circledR)}$ ) affected the dentinal tubules patency, it resulted in occlusion or narrowing of the open dentinal tubules to a various degrees over the different time periods. Vivasense ${ }^{\circledR}$ desensitizing varnish showed complete coverage of the dentinal tubules by resin material as an immediate result but it deteriorated with time.

\section{Acknowledgements}

Authors would like to thank The Saudi Dental Society for funding and supporting this research project by receiving the Dental Intern 
Research Grant 2015. Appreciation is also extended to the King Saud University, College of Dentistry.

\section{Funding}

None.

\section{Conflicts of interest}

The authors declare no conflict of interest.

\section{Clinical significance}

Lasers have been found to be effective for long term relief from dentinal hypersensitivity.

\section{References}

1. Ozen T, Orhan K, Avsever H, et al. Dentin hypersensitivity: a randomized clinical comparison of three different agents in a short-term treatment period. Oper Dent. 2009;34(4):392-398.

2. Miglani S, Aggarwal V, Ahuja B. Dentin hypersensitivity: Recent trends in management. J Conserv Dent 13(4): 218-224.

3. Bartold PM (2006) Dentinal hypersensitivity: a review. Aust Dent J. 2010;51:212-8;quiz 276.

4. Addy M, Hunter ML. Can tooth brushing damage your health? Effects on oral and dental tissues. Int Dent J. 2003;53 Suppl 3: 177-186.

5. Brannstrom M. Communication between the oral cavity and the dental pulp associated with restorative treatment. Oper Dent. 1984;9(2):57-68.

6. West NX, Lussi A, Seong J, et al. Dentin hypersensitivity: pain mechanisms and aetiology of exposed cervical dentin. Clin Oral Investig. 2013;17 Suppl 1:S9-S19.

7. Verma SK, Maheshwari S, Singh RK, et al. Laser in dentistry: An innovative tool in modern dental practice. Natl J Maxillofac Surg. 2012;3(2):124-132.

8. Asnaashari M, Moeini M. Effectiveness of lasers in the treatment of dentin hypersensitivity. J Lasers Med Sci. 2013;4(1):1-7.

9. http://www.waterlase.com/
10. Cavalli V, Reis AF, Giannini M, et al. The effect of elapsed time following bleaching on enamel bond strength of resin composite. Oper Dent. 2001;26(6):597-602.

11. Al-Saud LM, Al-Nahedh HN. Occluding effect of Nd:YAG laser and different dentin desensitizing agents on human dentinal tubules in vitro: a scanning electron microscopy investigation. Oper Dent. 2012;37(4):340-355.

12. Absi EG, Addy M, Adams D. Dentine hypersensitivity. A study of the patency of dentinal tubules in sensitive and non-sensitive cervical dentine. J Clin Periodontol. 1987;14(5):280-284.

13. Belal $\mathrm{MH}$, Yassin A. A comparative evaluation of $\mathrm{CO} 2$ and erbiumdoped yttrium aluminium garnet laser therapy in the management of dentin hypersensitivity and assessment of mineral content. J Periodontal Implant Sci. 2014;44(5):227-234.

14. Bader JB, Balevi P, Farsai C, et al. Lasers may reduce pain arising from dentin hypersensitivity. J Am Dent Assoc. 2014;145(4):e1-e2.

15. Namour A, Nammour S, Peremans A, et al. Treatment of dentinal hypersensitivity by means of Nd:YAP Laser: a preliminary in vitro study. Scientific World Journal. 2014:323604.

16. Umana M, Heysselaer D, Tielemans M, et al. Dentinal tubules sealing by means of diode lasers $(810$ and $980 \mathrm{~nm})$ : a preliminary in vitro study. Photomed Laser Surg. 2013;31(7):307-314.

17. Palazon MT, Scaramucci T, Aranha AC, et al. Immediate and short-term effects of in-office desensitizing treatments for dentinal tubule occlusion. Photomed Laser Surg. 2013;31(6):274-282.

18. Raichur PS, Setty SB, Thakur SL. Comparative evaluation of diode laser, stannous fluoride gel, and potassium nitrate gel in the treatment of dentinal hypersensitivity. Gen Dent. 2013;61(3):66-71.

19. Gholami GA, Fekrazad R, Esmaiel-Nejad A, et al. An evaluation of the occluding effects of Er;Cr:YSGG, Nd:YAG, CO2 and diode lasers on dentinal tubules: a scanning electron microscope in vitro study. Photomed Laser Surg. 2011;29(2):115-121.

20. http://www.ivoclarvevadent.us

21. http://www.kisdental.com

22. http://www.colgateprofessional.com 